\title{
Serum hepatitis $B$ virus ribonucleic acid and its influencing factors in chronic hepatitis B
}

\author{
Yifeng Zhou ${ }^{A-C, F}$, Yameng Peng ${ }^{B, C, F}$, Hao Yuan ${ }^{A, D-F}$, Zhenyi Long ${ }^{B, C, F}$, Sixian Wu ${ }^{B, C, F}$, Jiping Yang ${ }^{B, C, F}$ \\ Hunan Provincial People's Hospital, The First Affiliated Hospital of Hunan Normal University, Changsha, China \\ A - research concept and design; $\mathrm{B}$ - collection and/or assembly of data; $\mathrm{C}$ - data analysis and interpretation; \\ $D$ - writing the article; $E$ - critical revision of the article; $F$ - final approval of the article
}

\section{Address for correspondence}

Hao Yuan

E-mail: yuanha0696@sina.com

\section{Funding sources}

This work was supported by Health Commission of Hunan Provincial Research Project (C2019052)

\section{Conflict of interest}

All authors report no potential conflicts of interest with regard to this work

Received on June 1, 2020

Reviewed on June 4, 2020

Accepted on December 17, 2020

Published online on April 30, 2021
Cite as

Zhou Y, Peng Y, Yuan H, Long Z, Wu S, Yang J. Serum hepatitis B virus ribonucleic acid and its influencing factors in chronic hepatitis B. Adv Clin Exp Med. 2021;30(4):361-367. doi:10.17219/acem/131756

DOI

10.17219/acem/131756

\section{Copyright}

Copyright by Author(s)

This is an article distributed under the terms of the

Creative Commons Attribution 3.0 Unported (CC BY 3.0)

(https://creativecommons.org/licenses/by/3.0/)

\section{Abstract}

Background. Hepatitis B virus (HBV) remains one of the most serious and prevalent health problems in the world.

Objectives. To determine the serum hepatitis B virus (HBV) RNA levels in patients with chronic hepatitis B (CHB) with low HBV DNA levels and analyze the influencing factors.

Materials and methods. Seventy-two CHB patients with low HBV DNA levels were enrolled and divided into 2 groups according to hepatitis B e antigen (HBeAg) status; their age, sex, the incidence of HBV RNA level < lower limit of detection (LLD), and serum alanine aminotransferase (ALT), aspartate aminotransferase (AST), quantitative determination of HBsAg ( $(\mathrm{HBsAg}), \mathrm{HBV}$ DNA, and HBV RNA levels were compared. The factors influencing serum HBV RNA levels < LLD and the correlation between serum HBV RNA levels, and serum ALT, AST, qHBsAg and HBV DNA levels were analyzed.

Results. In HBeAg-positive patients, serum AST, qHBsAg and HBV RNA levels were higher, and serum HBV DNA levels and incidence of HBV RNA $<$ LLD were lower than those in HBeAg-negative patients $(p<0.05)$. Multivariate linear regression analysis revealed that HBeAg is a factor that significantly influences serum HBV RNA levels in patients with CHB $(p<0.05)$. Multivariate logistic regression analysis indicated that HBeAg and qHBsAg are factors that influence serum HBV RNA levels < LLD in patients with CHB. In HBeAg-positive patients, serum HBV RNA levels were positively correlated with qHBsAg and HBeAg.

Conclusions. The serum HBV RNA levels in CHB patients with low HBV DNA levels varied according to $\mathrm{HBeAg}$ status. The HBeAg is a factor that significantly influences serum HBV RNA levels in patients with CHB, while $H B$ eAg and qHBSAg are factors that significantly influence serum HBV RNA levels $<L L D$ in patients with CHB.

Key words: chronic hepatitis B, DNA, hepatitis B virus, pre-gene RNA, serum markers 


\section{Background}

Hepatitis B virus (HBV) infection remains one of the most serious and prevalent health problems in the world. ${ }^{1}$ Every year, 0.5-1.2 million patients die from liver decompensation, liver cirrhosis, liver failure, hepatocellular carcinoma, and other HBV-related diseases. ${ }^{2,3}$ The underlying cause of persistent $\mathrm{HBV}$ infection is the constant presence of covalently closed circular DNA (cccDNA). ${ }^{4}$ Further exacerbating the issue, existing serum markers and virological replication molecular assays are unable to accurately detect the presence of cccDNA in hepatocytes. Studies have demonstrated that despite the low concentration of HBV DNA in the serum of chronic hepatitis B (CHB) patients, cccDNA still actively replicates in vivo. This is evident through the observation of enhanced inflammation and fibrosis reported in liver histology. ${ }^{5}$ The monitoring of cccDNA in liver tissue requires an invasive liver biopsy, which is difficult to continuously implement in clinical practice. Additionally, the uneven distribution of cccDNA in liver tissue and the presence of relaxed circular doublestranded DNA (rcDNA) also increase the difficulty of detecting HBV. ${ }^{6}$

In 2017, The European Association for the Study of the Liver Clinical Practice Guidelines defined serum HBV RNA as a novel marker and pointed out that pre-gene RNA (pgRNA), a major component of HBV RNA, is released into the blood as a virus-like particle. ${ }^{1}$ The pgRNA is a direct transcript of cccDNA that accurately reflects the presence of cccDNA in hepatocytes. The ability to detect serum HBV RNA will provide more direct evidence of the status of viral replication and its therapeutic efficacy in patients with $\mathrm{CHB} .^{7}$ To this end, this study explores the presence and influencing factors of serum HBV RNA at low replication levels in patients with $\mathrm{CHB}$ and aims to provide new ideas for the clinical diagnosis and treatment of $\mathrm{CHB}$.

\section{Objectives}

This study explores the presence and influencing factors of serum HBV RNA at low replication levels in patients with $\mathrm{CHB}$ and aims to provide new ideas for the clinical diagnosis and treatment of $\mathrm{CHB}$.

\section{Materials and methods}

\section{Study criteria}

Our research was a retrospective case-control study. Inclusion criteria were as follows: patients who satisfy the relevant diagnostic criteria in the Guidelines for Prevention and Control of Chronic Hepatitis B (2015 Edition) (hereinafter referred to as the "Prevention and Control
Guidelines"). These criteria include: confirmed HBV infection for at least 6 months, and serum HBV DNA $<1.0 \times 10^{4}$ $\mathrm{U} / \mathrm{mL}$. Exclusion criteria were as follows: the diagnosis of other Hepadnaviridae infections, alcoholic liver disease, nonalcoholic fatty liver disease, drug-induced liver disease, liver injury due to metabolic and autoimmune liver disease or other causes, HIV-infected patients, and patients with primary biliary cirrhosis. ${ }^{8}$

\section{Ethics approval}

This study was performed according to the Declaration of Helsinki and approved by the Clinical Research Ethics Committee of Hunan Provincial People's Hospital (Ethical Application Ref: 2018S77), and each patient provided written informed consent before participation in the study. The research was conducted in compliance with institutional review board regulations.

\section{Subjects}

Patients with CHB who were definitively diagnosed in our hospital from May 2018 to July 2018 and who met the study criteria were selected. All patients had low levels of serum HBV DNA and were treated according to the Prevention and Control Guidelines ${ }^{8}$ after admission.

\section{Methodology}

\section{Sample collection and processing}

Five milliliters of fasting venous blood was collected in the morning and added to an anticoagulation tube. After centrifugation at $4000 \mathrm{rpm}$ for $10 \mathrm{~min}$ (centrifugation radius: $10 \mathrm{~cm}$ ), the supernatant was collected, dispensed into 1.5-mL enzyme-free Eppendorf (EP) tubes, and stored at $-80^{\circ} \mathrm{C}$ for further analysis.

\section{Serum HBV DNA detection}

The SLAN Real-Time PCR Detection System 96 fluorescence quantitative detector (Shanghai Hongshi Medical Technology Co., Ltd., Shanghai, China) was used to detect serum HBV DNA. The reagent was purchased from Hunan Sansure Biotech Inc. (Changsha, China) and the approved by the National Medical Products Administration (NMPA) quantitative polymerase chain reaction (qPCR) method was applied. Certified laboratory staff performed the assay in accordance with the instructions. The lower limit of detection (LLD) of the kit was $1.0 \times 10^{2} \mathrm{U} / \mathrm{mL}$.

\section{Detection of HBV serological markers (HBV-M)}

A fully automatic chemiluminescence immunoassay analyzer, Caris200 (Beijing Wantai BioPharm Co., Ltd., Beijing, China), was used to detect HBV serological markers 
(HBV-M). The reagent was a hepatitis B diagnostic kit purchased from Xiamen innoDx Biotechnology Co., Ltd (Xiamen, China). Detection was performed using the chemiluminescence microparticle immunoassay. The effective linear range of detection of hepatitis B surface antigen (HBsAg) was $0.05-250 \mathrm{U} / \mathrm{mL}$. Hepatitis B e antigen (HBeAg) was qualitatively detected.

\section{Detection of liver function indicators}

The Beckman 5800 fully automatic biochemical analyzer and the reagent purchased from Shanghai Kehua Bio-Engineering co., Ltd (Shanghai, China) were used to detect liver function. Serum alanine aminotransferase (ALT) and aspartate aminotransferase (AST) were used as observation indicators; both were detected using the dual-reagent rate method.

\section{Serum HBV RNA extraction and purification}

For HBV RNA detection, the HBV pre-genomic RNA (pgRNA) from all samples was extracted and purified using a nucleic acid extraction (DNA/RNA) or purification kit (magnetic beads method) from Sansure Biotech Inc. (Registration certificate for medical device No. 20173401141).

The detailed protocol was as follows: $200 \mu \mathrm{L}$ of each serum sample, $600 \mu \mathrm{L}$ of solution 1 and $100 \mu \mathrm{L}$ of solution 2 were added into EP tube and heated up to $60^{\circ} \mathrm{C}$ for $10 \mathrm{~min}$. The samples were then placed at room temperature for $10 \mathrm{~min}$. All tubes were placed on a magnetic rack for 3 min, after which the supernatant was discarded. Next, $600 \mu \mathrm{L}$ of solution 3 and $200 \mu \mathrm{L}$ of solution 4 were added to each tube. The tubes were then briefly vortexed and centrifuged. Then, they were placed on the magnetic rack for 3 min, after which the supernatant was carefully discarded. Next, $50 \mu \mathrm{L}$ of elution solution was added to each tube. The tubes were then vortexed and centrifuged briefly for $3 \mathrm{~min}$. Next, they were placed on a magnetic rack at room temperature for $10 \mathrm{~min}$. The solution was then transferred to new EP tubes and stored at $4^{\circ} \mathrm{C}$ for further use. Before HBV RNA detection, the purified nucleic acid was treated with DNase. Briefly, $16 \mu \mathrm{L}$ of each purified nucleic acid solution and $4 \mu \mathrm{L}$ of DNase solution were added to each PCR tube. The tubes were sealed and placed at $37^{\circ} \mathrm{C}$ for $30 \mathrm{~min}$ and then at $75^{\circ} \mathrm{C}$ for $10 \mathrm{~min}$. DNase-treated solutions were used for further HBV RNA detection.

\section{Serum HBV RNA detection}

The serum HBV RNA detection was processed using Hepatitis B Viral pregeno miRNA Quantitative Fluorescence Diagnostic Kit (PCR-Fluorescence Probing) from Sansure Biotech Inc. The kit's LOD was reported at 50 copies/mL.

The detailed protocol was as follows: $30 \mu \mathrm{L}$ of HBV RNA master mix was added to each PCR tube. Then, $20 \mu \mathrm{L}$ of purified and DNase-treated nucleic acid sample solution, purified HBV RNA quantitative reference RNA (A-B-C-D), as well as negative and positive RNA controls, were added to the PCR tubes. All PCR tubes were carefully sealed and placed into the Real-Time PCR Detection Systems (including Slan 96P (Shanghai Hongshi Medical Technology Co., Ltd., China) and ABI 7500 (Applied Biosystem, USA). The PCR program was run as follows: $95^{\circ} \mathrm{C}$ for $1 \mathrm{~min}, 60^{\circ} \mathrm{C}$ for $30 \mathrm{~min}$ and $95^{\circ} \mathrm{C}$ for $1 \mathrm{~min}$, and followed as 45 thermocycles as $95^{\circ} \mathrm{C}$ for $15 \mathrm{~s}$ and $60^{\circ} \mathrm{C}$ for $30 \mathrm{~s}$ with fluorescence detection. The results were analyzed according to the kit user manual.

\section{Observation indicators}

To compare patient age, sex, the incidence of HBV RNA below the LLD, as well as serum ALT, AST, qHBsAg, HBV DNA, and HBV RNA levels, all patients were divided into HBeAg-positive and HBeAg- negative patients according to their HBeAg status. The serum HBV RNA levels in patients with $\mathrm{CHB}$ and factors which influence serum HBV RNA levels that were below the LLD were analyzed. The correlation of serum HBV RNA levels with serum ALT, AST, qHBsAg, and serum HBV DNA levels was also analyzed.

\section{Statistical methods}

Data were processed using the SPSS v. 19.0 statistical software (IBM Corp., Armonk, USA). Statistical graphs were plotted using GraphPad Prism 6.0 (GraphPad Software, San Diego, USA). Logarithmic transformation (log) was adopted for all laboratory data used for serum detection of patients with CHB. Quantitative data that satisfied normal distribution were expressed by $\mathrm{x} \pm \mathrm{s}$, and the paired t-test was used for comparison between both groups. Pearson correlation analysis was applied; non-normally distributed measurement data were expressed using M (P25, P75) after logarithmic transformation. The Mann-Whitney $\mathrm{U}$ test was used for intergroup comparison, and Spearman's rank correlation analysis was applied; enumeration data were expressed as percentages. The $\chi^{2}$ test was used for intergroup comparison; linear regression analysis and binary logistic regression analysis were used to analyze the influencing factors of HBV RNA. A p-value $<0.05$ was used to indicate statistical significance.

\section{Results}

Seventy-two cases of $\mathrm{CHB}$ patients with low levels of HBV DNA were included in this study. The average age of the patients was $49.49 \pm 13.539$ years. Among them, 46 were men and 26 were women. Among the 72 patients, 12 were $\mathrm{HBeAg}$-positive and 60 were $\mathrm{HBeAg}$-negative. There was no statistically significant difference in terms 
Table 1. Comparison of clinical data between HBeAg-positive and HBeAg-negative patients

\begin{tabular}{|l|c|c|c|c|}
\hline \multicolumn{1}{|c|}{ Variable } & HBeAg-positive & HBeAg-negative & Test statistic & p-value \\
\hline N & 12 & 60 & - & - \\
\hline Age [years] & $40.4 \pm 10.5$ & $51.3 \pm 13.4$ & $-2.649^{\dagger}$ & 0.01 \\
\hline Sex (male/female) & $9 / 3$ & $37 / 23$ & $0.301^{\ddagger}$ & 0.58 \\
\hline ALT (M (P25, P75)) $[\mathrm{U} / \mathrm{L}]$ & $1.74(1.44,1.95)$ & $1.39(1.19,1.70)$ & $210^{\S}$ & 0.23 \\
\hline AST (M (P25, P75)) [U/L] & $1.63(1.52,1.94)$ & $1.40(1.27,1.64)$ & $191^{\S}$ & 0.011 \\
\hline qHBSAg (M (P25, P75)) $[\mathrm{U} / \mathrm{mL}]$ & $3.45(1.46,3.77)$ & $2.74(1.34,3.23)$ & $216^{\S}$ & 0.03 \\
\hline HBV DNA (M (P25, P75)) $[\mathrm{U} / \mathrm{mL}]$ & $2.06(2.00,2.88)$ & $2.93(2.68,3.19)$ & $174^{\S}$ & 0.005 \\
\hline HBV RNA (M (P25, P75)) $[\mathrm{U} / \mathrm{mL}]$ & $2.39(1.70,4.69)$ & $1.70(1.70,1.74)$ & $212^{\S}$ & 0.007 \\
\hline HBV RNA below the LLD, $n(\%)$ & $5(42.0)$ & $44(73.0)$ & $4.613^{\ddagger}$ & 0.032 \\
\hline
\end{tabular}

Data are expressed as means \pm standard deviation (SD). † t-value; $\neq x^{2}$-value; $§$ Z-value; HBV - hepatitis B virus; HBeAg - hepatitis B e antigen; LLD - Iower limit of detection; ALT - alanine aminotransferase; AST - aspartate aminotransferase; qHBsAg - quantitative determination of HBsAg.

of sex or serum ALT levels between HBeAg-positive and HBeAg-negative patients ( $\mathrm{p}>0.05$ ). HBeAg-positive patients were younger than HBeAg-negative patients; their serum AST, qHBsAg and HBV RNA levels were higher than those in HBeAg-negative patients, while their serum HBV DNA levels and incidence of HBV RNA below the LLD were lower than those in $\mathrm{HBeAg}$-negative patients. These differences were statistically significant ( $\mathrm{p}<0.05$, Table 1 ).

To perform the univariate linear regression analysis, age (assigned value: continuous variable), $\operatorname{sex}($ men $=1$, women = 2), ALT (assigned value: continuous variable), AST (assigned value: continuous variable), qHBsAg (assigned value: continuous variable), $\mathrm{HBeAg}$ (assigned value: HBeAg-positive = 0, HBeAg-positive = 1), and HBV DNA (assigned value: continuous variable) were taken as independent variables. Further, serum HBV RNA (assigned value: continuous variable) was taken as the dependent variable. The results demonstrated that age, AST, qHBsAg, and $\mathrm{HBeAg}$ are factors that significantly influence serum HBV RNA levels in patients with CHB ( $\mathrm{p}<0.05)$. Independent variables with $\mathrm{p}<0.20$ in the univariate analysis were included in the multivariate linear regression analysis. The results demonstrated that $\mathrm{HBeAg}$ is a factor that significantly influences serum HBV RNA levels in patients with CHB ( $<<0.05$, Table 2).
To perform multivariate logistic regression analysis of the factors which influence serum HBV RNA levels to be below the LLD, age (assigned value: continuous variable), sex $($ men $=1$, women $=2)$, ALT (assigned value: continuous variable), AST (assigned value: continuous variable), qHBsAg (assigned value: continuous variable), $\mathrm{HBeAg}$ (assigned value: $\mathrm{HBeAg}$-positive $=0, \mathrm{HBeAg}$-positive = 1), and HBV DNA (assigned value: continuous variable) were taken as independent variables. Whether serum HBV RNA was below the LLD (assigned value: yes $=1$, no $=0$ ) was taken as the dependent variable. The results demonstrated that $\mathrm{HBeAg}$ (odds ration $(\mathrm{OR})=3.85,95 \%$ confidence interval $(95 \% \mathrm{CI})[1.068,13.880], \mathrm{p}<0.039)$ and $\mathrm{qHBsAg}$ $(\mathrm{OR}=1.682,95 \% \mathrm{CI}[1.055,2.681], \mathrm{p}<0.029)$ are factors which significantly influence serum HBV RNA levels to be below the LLD in patients with CHB.

Serum HBV RNA in patients with $\mathrm{CHB}$ was positively correlated with qHBsAg $(\mathrm{r}=0.322, \mathrm{p}=0.006)$ (Fig. 1A) and HBeAg $(r=0.235, p=0.047)$ (Fig. 1B) but was not correlated with ALT $(r=0.038, p=0.752)$, AST $(r=0.189$, $\mathrm{p}=0.557)$ or HBV DNA $(\mathrm{r}=0.058, \mathrm{p}=0.629)$.

In HBeAg-positive patients, serum HBV RNA levels were positively correlated with qHBsAg $(\mathrm{r}=0.848$; $\mathrm{p} \leq 0.001)$ (Fig. 1C) and HBeAg ( $\mathrm{r}=0.725 ; \mathrm{p}=0.008)$ (Fig. 1D) but were not correlated with ALT $(r=0.051, \mathrm{p}=0.876)$, AST

Table 2. Univariate and multivariate linear regression analysis of factors influencing serum HBV RNA levels in CHB patients

\begin{tabular}{|c|c|c|c|c|c|c|c|c|}
\hline \multirow{2}{*}{ Variable } & \multirow{2}{*}{ B } & \multicolumn{2}{|c|}{ Univariate analysis } & \multirow{2}{*}{$p$-value } & \multicolumn{4}{|c|}{ Multivariable analysis } \\
\hline & & $\overline{S D}$ & t-value & & $\bar{B}$ & $\overline{S D}$ & t-value & $p$-value \\
\hline Age & -0.024 & 0.009 & -2.770 & 0.007 & -0.012 & 0.009 & -1.368 & 0.247 \\
\hline Sex & -0.256 & 0.254 & -1.007 & 0.317 & - & - & - & - \\
\hline ALT & 0.292 & 0.300 & 0.976 & 0.332 & - & - & - & - \\
\hline AST & 0.651 & 0.388 & 1.678 & 0.098 & 0.373 & 0.368 & 1.014 & 0.314 \\
\hline qHBsAg & 0.273 & 0.092 & 2.956 & 0.004 & 0.167 & 0.093 & 1.795 & 0.077 \\
\hline $\mathrm{HBeAg}$ & 1.164 & 0.299 & 3.897 & $<0.001$ & 0.837 & 0.318 & 2.634 & 0.010 \\
\hline HBV DNA & 0.05 & 0.224 & 0.222 & 0.825 & - & - & - & - \\
\hline
\end{tabular}

HBV - hepatitis B virus; CHB - chronic hepatitis B; SD - standard deviation; HBeAg - hepatitis B e antigen; ALT - alanine aminotransferase; AST - aspartate aminotransferase; qHBsAg - quantitative determination of HBsAg. 

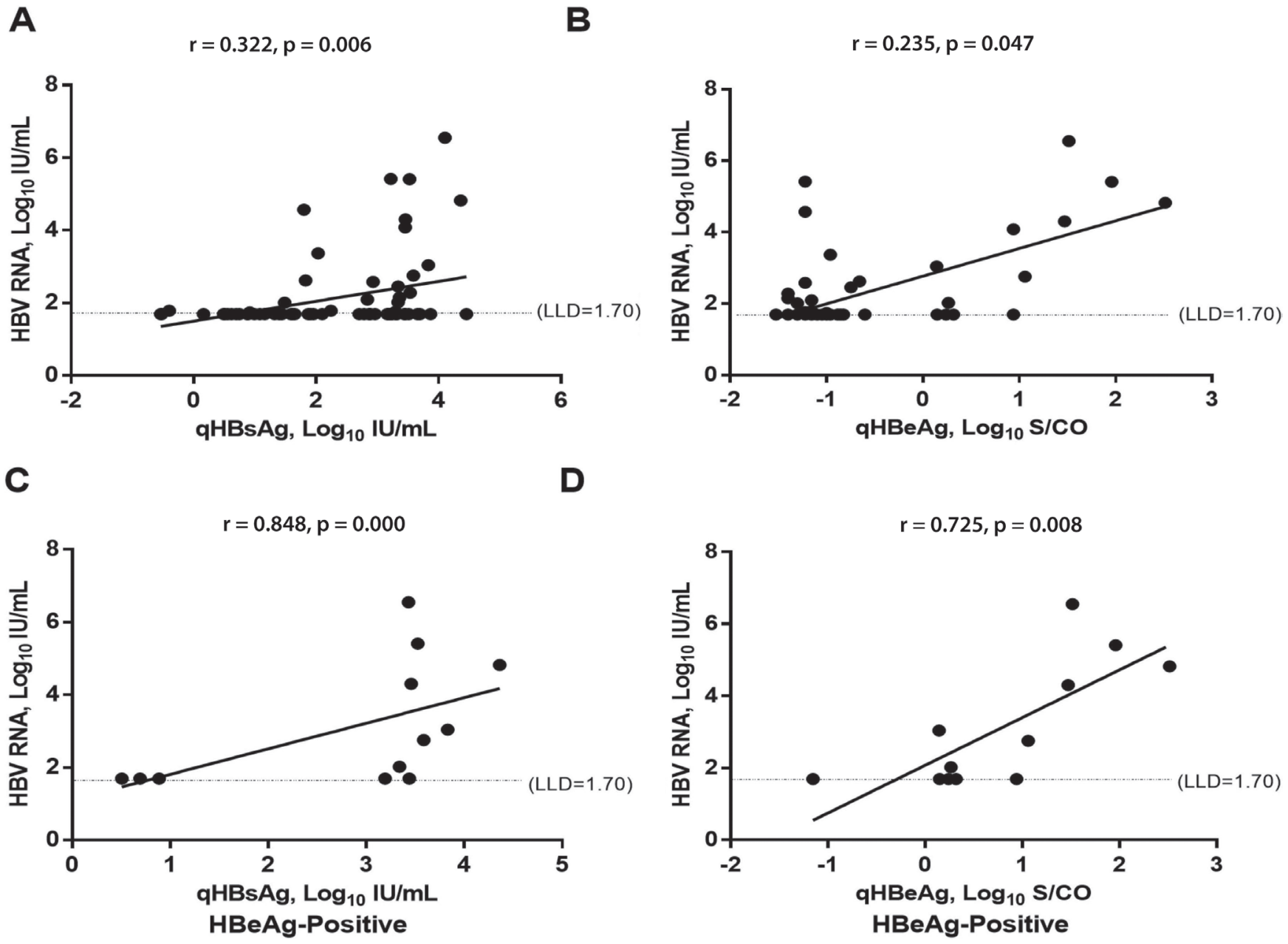

Fig. 1. Correlation of HBV RNA with serum levels of $\mathrm{qHBsAg}$ and HBeAg. The LLD for the HBV RNA PCR is $50 \mathrm{U} / \mathrm{mL}(1.70 \mathrm{log} 10 \mathrm{U} / \mathrm{mL})$

$(\mathrm{r}=0.046, \mathrm{p}=0.702)$ or HBV DNA $(\mathrm{r}=0.383, \mathrm{p}=0.219)$. In HBeAg-negative patients, serum HBV RNA was not significantly correlated with $\mathrm{qHBsAg}(\mathrm{r}=0.151, \mathrm{p}=0.251)$, $\operatorname{HBeAg}(\mathrm{r}=0.083, \mathrm{p}=0.529), \operatorname{ALT}(\mathrm{r}=-0.020, \mathrm{p}=0.878)$, AST $(r=-0.080, p=0.542)$, or HBV DNA $(r=0.145$, $\mathrm{p}=0.268)$.

\section{Discussion}

The current treatment of patients with $\mathrm{CHB}$ remains challenging, with difficulties in drug discontinuation and easy rebound among the issues. Existing serological markers do not accurately reflect the existence of cccDNA in hepatocytes. ${ }^{9}$ In 1996, when studying whether HBV can infect human peripheral blood mononuclear cells, Kock et al. ${ }^{10}$ detected HBV RNA in the serum of patients with CHB. In recent years, both national and international studies have conducted extensive research on continuously improving and optimizing HBV detection methods, and further exploring the clinical implications of serum HBV RNA.7,9,11,12

The Prevention and Control Guidelines suggest that the ideal treatment-endpoint for HBeAg-positive and
HBeAg-negative patients with $\mathrm{CHB}$ is the clinical observation of sustained HBsAg clearance, with or without seroconversion after drug withdrawal. ${ }^{8}$ However, HBsAg cannot accurately reflect the replication of HBV in hepatocytes. Furthermore, the $\mathrm{HBeAg}$-negative conversion rate is not an ideal marker of $\mathrm{CHB}$ pathogenesis during the actual treatment. This study compared serum HBV RNA levels in $\mathrm{HBeAg}$-positive and $\mathrm{HBeAg}$-negative patients with $\mathrm{CHB}$ with low levels of HBV DNA replication and found significant differences in serum HBV RNA levels between both groups. The results of this study demonstrated that $\mathrm{HBeAg}$-positive patients were younger than HBeAgnegative patients; this was similar to the results obtained by Yang et al. ${ }^{13}$ In that study, the authors suggested that the incidence of negative HBeAg correlated with age. Further analysis of potential influencing factors demonstrated that $\mathrm{HBeAg}$ is a factor that significantly influences serum HBV RNA levels in patients with CHB. Further, we observed that serum HBV RNA was positively correlated with $\mathrm{HBeAg}$ in patients with $\mathrm{CHB}$, and serum HBV RNA levels were positively correlated with $\mathrm{HBeAg}$ in HBeAgpositive patients. These data indicate that serum HBV RNA can accurately reflect the replication status of the virus 
in patients with CHB. In a previous study, Huang et al. ${ }^{14}$ found that serum HBV RNA levels may be used as a serological marker for predicting the seroconversion of $\mathrm{HBeAg}$ during treatment with nucleosides and nucleotides. ${ }^{15}$

While, to a certain extent, HBV DNA can reflect the replication activity of cccDNA in vivo, the low detection rate of HBV RNA is consistent with this phenomenon. ${ }^{5}$ However, serum HBV DNA below the lower limit of detection only indicates that the reverse transcription process of the virus is inhibited and cannot reflect the transcriptional status of cccDNA. After the reverse transcription process is inhibited, cccDNA still produces progeny virus in the form of HBV RNA virus-like particles. ${ }^{5}$ Therefore, following drug withdrawal on the premise of existing virological response, the rates of disease rebound, and recurrence are higher. ${ }^{5,12,16,17}$ The results of this study demonstrate that there was no correlation between serum HBV DNA and HBV RNA in patients with CHB, and that serum HBV DNA was not correlated with HBV RNA in patients with different $\mathrm{HBeAg}$ status. These data indicate that even when HBV DNA is at a low level or below the lower limit of detection, cccDNA maintains its replication activity which results in HBV RNA being detected at a relatively high level. Thus, serum HBV RNA can reflect the presence of cccDNA more accurately than serum HBV DNA, thereby providing more powerful evidence for the efficacy of antiviral treatment in patients with CHB. ${ }^{5,18,19}$

The incidence of serum HBV RNA below the lower limit of detection is higher in HBeAg-negative patients than in $\mathrm{HBeAg}$-positive patients. This may be due to the higher cccDNA transcriptional activity in HBeAg-positive patients compared to HBeAg-negative patients, which is consistent with findings from other studies. ${ }^{20}$ Multivariate logistic regression analysis revealed that $\mathrm{qHBsAg}$ and $\mathrm{HBeAg}$ are factors that influence serum HBV RNA below the lower limit of detection in patients with CHB. In this study, the total detection rate of serum HBV RNA in patients with CHB was $32 \%$ (23/72), which was similar to the detection rate in the study by Huang et al. ${ }^{12}$ However, the detection rate in the study conducted by Li et al. ${ }^{21}$ was $85.3 \%$. Among other factors, this difference may be due to sample selection, demographic characteristics and variable methodology.

The results of this study demonstrate that serum HBV RNA is positively correlated with HBsAg in HBeAg-positive patients; however, there is no significant correlation between the two in HBeAg-negative patients. This may be because HBsAg can be synthesized, not only from cccDNA but also from the integrated HBV gene fragments. Studies have shown that in HBV-infected patients, hepatocytes carrying integrated HBV DNA fragments account for approx. $1 \%$ of total hepatocytes and that HBV DNA is transcribed and translated into HBsAg after integration. This may be an important factor that contributes to the failure to completely clear $\mathrm{HBeAg}$ in clinical practice..$^{22,23}$ Therefore, HBsAg has certain shortcomings in terms of judging whether patients have reached the level of clinical cure. In contrast, serum HBV RNA is a direct transcript of cccDNA, and can more directly reflect the replication activity of cccDNA in vivo compared with HBsAg. Several studies have suggested that HBV RNA should be included in the clinical diagnosis, disease progression monitoring and the rational withdrawal of antiviral drugs. ${ }^{24-26}$ However, its use as an established serum marker in clinical practice still requires more accurate, sensitive, and standardized detection methods, as well as more sophisticated prospective studies.

\section{Limitations}

The main limitation of our study was the size of the study sample.

\section{Conclusions}

There is a marked difference in serum HBV RNA levels in CHB patients with low HBV DNA levels and different HBeAg statuses. The HBeAg is a factor that influences serum HBV RNA levels in patients with $\mathrm{CHB}$, while $\mathrm{HBeAg}$ and $\mathrm{qHBsAg}$ are factors that influence serum HBV RNA levels to be below the lower limit of detection in patients with CHB. Concurrently, serum HBV RNA levels in patients with $\mathrm{CHB}$ are correlated with other serological markers. This suggests that serum HBV RNA levels in patients with $\mathrm{CHB}$ with low HBV DNA levels can reflect virus activity to a certain extent. We, thus, believe that HBV RNA can be utilized as a novel serum marker for the detection of HBV infection.

\section{ORCID iDs}

Yifeng Zhou (D) https://orcid.org/0000-0002-7590-4894 Yameng Peng (D) https://orcid.org/0000-0001-5667-6702 Hao Yuan (D) https://orcid.org/0000-0003-2573-7669

Zhenyi Long (D) https://orcid.org/0000-0002-9078-2469

Sixian Wu (D) https://orcid.org/0000-0002-0863-6324

Jiping Yang (D) https://orcid.org/0000-0002-4119-6420

\section{References}

1. European Association for the Study of the Liver. EASL 2017 Clinical Practice Guidelines on the management of hepatitis B virus infection. J Hepatol. 2017;67(2):370-398. doi:10.1016/j.jhep.2017.03.021

2. Liaw Y, Chu C. Hepatitis B virus infection. Lancet. 2009;373(9663): 582-592. doi:10.1016/S0140-6736(09)60207-5

3. Yim HJ, Hussain M, Liu Y, Wong SN, Fung SK, Lok ASF. Evolution of multi-drug resistant hepatitis $B$ virus during sequential therapy. Hepatology. 2006;44(3):703-712. doi:10.1002/hep.21290

4. Nassal M. HBV cccDNA: Viral persistence reservoir and key obstacle for a cure of chronic hepatitis B. Gut. 2015;64(12):1972-1984. doi:10. 1136/gutjnl-2015-309809

5. Lu F M, Wang J, Chen X M, et al. The potential use of serum HBV RNA to guide the functional cure of chronic hepatitis B. Zhonghua Gan Zang Bing Za Zhi. 2017;25(2):105-110. doi:10.3760/cma.j.issn.10073418.2017.02.005

6. Jinhong $Z$, Man WX. Clinical significance of serum HBV cccDNA in patients with hepatitis B. J Pract Med. 2013;29(3):395-397. doi:10. 3969/j.issn.1006-5725.2013.03.021 
7. Wang J, Shen T, Huang X, et al. Serum hepatitis B virus RNA is encapsidated pregenome RNA that may be associated with persistence of viral infection and rebound. J Hepatol. 2016;65(4):700-710. doi:10. 1016/j.jhep.2016.05.029

8. Hou J, Wang G, Wang F, et al; Chinese Society of Hepatology and Chinese Society of Infectious Diseases (Chinese Medical Association). The guideline of prevention and treatment for chronic hepatitis B: A 2015 update. J Clin Hepatol. 2015;31(12):1941-1960. doi:10.14218/ JCTH.2016.00019

9. Halgand B, Desterke C, Riviere L, et al. Hepatitis B virus pregenomic RNA in hepatocellular carcinoma: A nosological and prognostic determinant. Hepatology. 2018;67(1):86-96. doi:10.1002/hep.29463

10. Su Q, Wang SF, Chang TE, et al. Circulating hepatitis B virus nucleic acids in chronic infection: Representation of differently polyadenylated viral transcripts during progression to nonreplicative stages. Clin Cancer Res. 2001;7(7):2005-2015. PMID:11448918

11. Rokuhara A, Matsumoto A, Tanaka E, et al. Hepatitis B virus RNA is measurable in serum and can be a new marker for monitoring lamivudine therapy. J Gastroenterol. 2006;41(8):785-790. doi:10.1007/s00535006-1856-4

12. Huang $Y$, Chayama K, Tsuge M, et al. Differential effects of interferon and lamivudine on serum HBV RNA inhibition in patients with chronic hepatitis B. Antivir Ther. 2010;15(2):177-184. doi:10.3851/IMP1508

13. Gong YJ, Bing $\mathrm{H}$, Bang QJ, et al. Clinical analysis of the relationship between the incidence of hepatitis $B$ e antigen-negative chronic hepatitis B and age. Clin Focus. 2008:23(7):502-503. doi:10.3969/j. issn.1004-583X.2008.07.021.

14. Huang Y, Takahashi S, Tsuge M, et al. On-treatment low serum HBV RNA level predicts initial virological response in chronic hepatitis $B$ patients receiving nucleoside analogue therapy. Antivir Ther. 2015; 20(4):369-375. doi:10.3851/IMP2777

15. Tsuge $M$, Murakami E, Imamura $M$, et al. Serum HBV RNA and HBeAg are useful markers for the safe discontinuation of nucleotide analogue treatments in chronic hepatitis B patients. J Gastroenterol. 2013; 48(10):1188-1204. doi:10.1007/s00535-012-0737-2

16. Wang J, Yu Y, Li G, et al. Natural history of serum HBV-RNA in chronic HBV infection. JViral Hepat. 2018;25(9):1038-1047. doi:10.1111/jvh.12908
17. Xia LR, Cheng PX, Jian G. Clinical value of serum HBV RNA. J Clin Hepatol. 2017;33(11):2196-2199. doi:10.3969/j.issn.1001-5256.2017. 11.032

18. Butler EK, Gersch J, McNamara A, et al. Hepatitis B serum DNA and RNA levels in nucleos(t)ide analogue-treated or untreated patients during chronic and acute infection. Hepatology. 2018;68(6):2106-2117. doi:10.1002/hep.30082

19. Tsuge M, Chayama K. Availability of monitoring serum HBV DNA plus RNA during nucleot(s)ide analogue therapy. J Gastroenterol. 2013; 48(6):779-780. doi:10.1007/s00535-013-0801-6

20. Lu F, Wang J, Chen X, Xu D, Xia N. Potential use of serum HBV RNA in antiviral therapy for chronic hepatitis B in the era of nucleos(t) ide analogs. Front Med. 2017;11(4):502-508. doi:10.1007/s11684-0170590-z

21. Li Y, He L, Li Y, et al. Characterization of serum HBV RNA in patients with untreated $\mathrm{HBeAg}$-positive and -negative chronic hepatitis B infection. Hepatitis Monthly. 2018,18(2):e62079. doi:10.5812/hepatmon. 62079.

22. Chan HLY, Wong VWS, Chim AML, Chan HY, Wong GLH, Sung JJY. Serum HBsAg quantification to predict response to peginterferon therapy of e antigen positive chronic hepatitis B. Aliment Pharmacol Ther. 2010;32(11):1323-1331. doi:10.1111/j.1365-2036.2010.04474.x

23. Höner zu Siederdissen C, Maasoumy B, Cornberg M. What is new on $\mathrm{HBsAg}$ and other diagnostic markers in HBV infection? Best Pract Res Clin Gastroenterol. 2017;31(3):281-289. doi:10.1016/j.bpg.2017.04.009

24. Wang J, Yu YQ, Li GJ, et al. Relationship between serum HBV-RNA levels and intrahepatic viral as well as histologic activity markers in entecavir-treated patients. J Hepatol. 2018;68(1):16-24. doi:10.1016/j.jhep. 2017.08.021

25. van Bommel F, van Bommel A, Krauel A, et al. Serum HBV RNA as a predictor of peginterferon alfa-2a (40KD) response in patients with $\mathrm{HBeAg}$ positive chronic hepatitis B. J Infect Dis. 2018;218(7):1066-1074. doi:10. 1093/infdis/jiy270

26. van Campenhout $\mathrm{M}$, van Bommel F, Pfefferkorn $\mathrm{M}$, et al. Host and viral factors associated with serum hepatitis B virus RNA levels among patients in need for treatment. Hepatology. 2018;68(3):839-847. doi:10.1002/hep.29872 